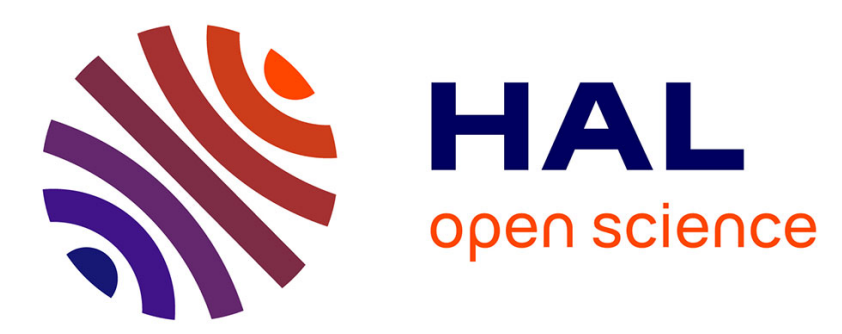

\title{
Reactive or Proactive? Age Differences in the Use of Affective Regulation Strategies
}

Sarah Le Vigouroux, Jean-Baptiste Pavani, Bruno Dauvier, Jean-Luc Kop, Anne Congard

\section{- To cite this version:}

Sarah Le Vigouroux, Jean-Baptiste Pavani, Bruno Dauvier, Jean-Luc Kop, Anne Congard. Reactive or Proactive? Age Differences in the Use of Affective Regulation Strategies. Psychology and Aging, 2017, 32 (7), pp.621-627. 10.1037/pag0000197 . hal-01772239

\section{HAL Id: hal-01772239 \\ https://hal.science/hal-01772239}

Submitted on 3 May 2018

HAL is a multi-disciplinary open access archive for the deposit and dissemination of scientific research documents, whether they are published or not. The documents may come from teaching and research institutions in France or abroad, or from public or private research centers.
L'archive ouverte pluridisciplinaire HAL, est destinée au dépôt et à la diffusion de documents scientifiques de niveau recherche, publiés ou non, émanant des établissements d'enseignement et de recherche français ou étrangers, des laboratoires publics ou privés. 
${ }^{a}$ Center for Research on the Psychology of Cognition, Language and Emotion (PsyCLE), Aix-Marseille University, Aix-en-Provence, France

${ }^{\mathrm{b}}$ Interpsy laboratory (2LPN project, CEMA team), University of Lorraine, Nancy, France

Correspondence concerning this article should be addressed to Sarah Le Vigouroux,

8 Université d'Aix-Marseille, Centre PsyCLE (EA 3273), Maison de la Recherche, 29 avenue

9 Schuman, 13621 Aix-en-Provence Cedex 1, France. E-mail: sarah.le-vigouroux@univ-amu.fr

The data used in this study were collected as part of a dissertation on the development of emotion regulation, focusing on the idea of timing (reactive and proactive regulation). The results reported in this study have not been published elsewhere. 
2 We examined age-related differences in the reactive and proactive use of affect regulation

3 strategies. We collected data from 209 participants aged 13-80 years, using an experience

4 sampling method. The most interesting finding was that, as hypothesized, compared with the

5 under-20s, adults aged 20 years and over used the two strategies we focused on (i.e., problem

6 solving and positive reappraisal) more intensely and in a reactive manner. By contrast, from

7 the age of about 55 years upwards, adults were characterized by a more intensely proactive

8 use of these strategies. Results are discussed in the light of age differences in motivation.

9 Keywords: affect regulation, affective experience, experience sampling method,

10 eudaimonic vs hedonic

11 Abstract: 99 words

12 Text: 264 lines 
Research on emotional aging has revealed a paradox whereby adults in their 60s tend to feel more positive affect (PA) and/or less negative affect (NA) than adults aged 20-30 years (Carstensen et al., 2011; Gross et al., 1997; Mroczek \& Kolarz, 1998; Riediger, Voelkle, Ebner, \& Lindenberger, 2011). This finding has frequently been interpreted as reflecting the fact that older adults have better affective skills and greater motivation than their younger counterparts. A recent systematic review provided support for this idea (Doerwald, Scheibe, Zacher, \& Van Yperen, 2016), by showing that older adults regulate their affect in a slightly more efficient manner than younger adults. These age differences in affect regulation may, in turn, arise from age differences in some motivational factors.

\section{Age Differences in Affect Regulation Motivation (Hedonic vs. Eudaimonic Approach)}

The potential role of motivation is stressed by two theories that were developed to explain age differences in affective feeling and affect regulation: socioemotional selectivity theory (SST; Carstensen, 2006) and strength and vulnerability integration (SAVI) theory (Charles, 2010). Albeit not equivalent, these two theories both postulate that, with advancing age, future time perception decreases, inducing changes in the fundamental goals individuals are motivated to pursue. Compared with older adults, younger adults are assumed to adopt a more eudaimonic approach to well-being (Ryan \& Deci, 2001), focused on their self-development.

Young adults see no limits to their future time, leading them to pursue goals that tend to promote their future well-being at the expense of their immediate one (e.g., accumulating new knowledge through education) (Lang \& Carstensen, 2002). By contrast, as they become aware of the more limited time they have left to live (Löckenhoff \& Carstensen, 2007), older adults adopt a more hedonic approach to wellbeing (Kahneman, Diener, \& Schwarz, 1999), focused on the goal of cultivating their immediate well-being. 
Pursuing this goal appears to lead older adults to use some affect regulation strategies more intensely than younger adults do (Doerwald et al., 2016), as these strategies effectively promote immediate well-being (Charles \& Pasupathi, 2003; Pavani, Le Vigouroux, Kop, Congard, \& Dauvier, 2015; Röcke, Li, \& Smith, 2009). The precise way in which these age differences in motivation lead younger and older adults to differ in the intensity with which they implement various affect regulation strategies has received considerable attention (e.g., Diehl et al., 2014; Diehl, Coyle, \& Labouvie-Vief, 1996; Le Vigouroux et al., 2015; Rovenpor, Skogsberg, \& Isaacowitz, 2012). By contrast, little is known about how age influences the reactive versus proactive use of affect regulation strategies, even though this construct appears to be key to the effectiveness of affect regulation (Carstensen, Fung, \& Charles, 2003; Gross, 1998).

\section{Age Differences in Affect Regulation Timing: Reactive Versus Proactive}

Affect regulation can take place either before or after the experience of an affect (Voelkle, Ebner, Lindenberger, \& Riediger, 2013). On this basis, Gross (Gross, 1998, 2015; Gross \& Thompson, 2007) distinguished between response- and antecedent-focused affect regulation strategies. Response-focused (i.e., reactive) strategies are strategies used in reaction to an affect that is already present, and are designed to modify this elicited affect. Antecedentfocused (i.e., proactive) strategies are strategies that target the antecedents of an affect, and involve modifying the information input before that affect occurs.

Gross (1998)'s assumption that some strategies are always reactive (e.g., expressive suppression) whereas others are always proactive (e.g., positive reappraisal) appears to be inaccurate. Indeed, the most recent version of his own model of affect regulation (Gross, 2015) stresses the complexity of the dynamics of affect regulation, which is described as a continuum of processes taking place either before, during, or after an affect. Thus, the time at which an affect regulation strategy is used in relation to the targeted affect may be the only 
criterion for accurately categorizing a strategy as reactive or proactive. In the present study, given that the affects that individuals most often want to modify are high NA and low PA (Riediger, Schmiedek, Wagner, \& Lindenberger, 2009), we defined reactive strategies as those affect regulation strategies used after a high NA/low PA state. Proactivity is more difficult to assess experimentally, as the targeted affect may never happen if the regulation is successful. Thus, proactive strategies cannot be defined as the strategies used before high NA/low PA states. That said, strategies used after low NA/high PA are, by definition, not reactive, and can be regarded as a preventive measure to limit a future increase in NA or decrease in PA.

We hypothesized that age differences in motivation would lead younger and older individuals to differ in their use of reactive and proactive affect regulation strategies. Assuming that younger adults are less motivated to cultivate their immediate well-being than older adults, they may only use affect regulation strategies when their well-being has been reduced by unpleasant events, for example (i.e., in a reactive manner). Furthermore, their eudaimonic approach to well-being may precisely expose them to unpleasant events, leading to increasing use of strategies to deal with them. By contrast, if one of the main goals of older adults is to cultivate their immediate well-being, then they may use affect regulation strategies more intensely, not only in reaction to a low level of well-being, but also when its level is already high, for instance in an already pleasant situation (i.e., in a proactive manner).

\section{The Present Study}

The aim of this study was to examine age differences in the reactive and proactive use of affect regulation strategies. For the reasons set out above, reactive regulation referred to strategies used in response to a high level of NA or low level of PA. By contrast, proactive regulation referred to strategies used when an individual experiences a low level of NA or high level of PA. The strategies we analyzed were problem solving (i.e., behavioral effort to 
take concrete actions to change a situation perceived of as unpleasant) and positive reappraisal (i.e., cognitive effort to evaluate a situation that was initially perceived of as unpleasant in a more favorable fashion). We focused on these two strategies because they are widely studied strategies that are known to be effective in enhancing wellbeing (e.g., Pavani et al., 2015), they can be used either proactively or reactively (Blanchard-Fields, Stein, \& Watson, 2004; Urry, 2009), and their use changes with age (Doerwald et al., 2016). Innovative use of an experience sampling method (ESM; Hektner, Schmidt, \& Csikszentmihalyi, 2008) and refined statistical tools such as generalized additive mixed models (GAMMs; McKeown \& Sneddon, 2014) allowed us to test two hypotheses.

Our first hypothesis was that older adults use affect regulation strategies (i.e., problem solving and positive reappraisal) more intensely than younger adults. Our second hypothesis, which referred to age differences in strategy timing, was that a) compared with adolescents, young adults use these strategies more intensely reactively, and b) compared with younger adults, older ones use these strategies more intensely proactively. In other words, older adults make intense use of regulation strategies both reactively and proactively.

\section{Method}

\section{Participants}

The sample consisted of 209 nonclinical individuals (131 women) ranging in age from 13 to 80 years $(M=38.50, S D=17.56)$. It included 39 participants aged 13-20 years, 51 aged 21-30 years, 56 aged 31-50 years, 52 aged 51-70 years, and 11 aged 70 years or over. Participants were recruited from the experimenters' social networks, and came from various regions of France. The study met local ethical rules on noninvasive protocols involving healthy participants and did not require formal ethics committee approval. All participants signed an informed consent form, which outlined the conditions for taking part, as well as for withdrawing from the study, if desired. 


\section{Procedure}

An initial interview was conducted to establish the list of 14 items that participants would subsequently be asked to rate during the ESM phase (for more information, see "Affects and strategies" subsection below). The ESM phase lasted 2 consecutive weeks, during which participants rated the 14 selected items 5 times a day, in response to alerts sent to their mobile phones from a central server. Each participant could adjust the timing of these alerts (usually at 9 am, midday, $3 \mathrm{pm}, 6 \mathrm{pm}$ and $9 \mathrm{pm}$ ) by up to 15 minutes. After receiving an alert message, they had 30 minutes to respond, using the reply function of their mobile phone. For the affect items, participants were asked to indicate their current level of feeling, whereas for the strategies, the focus was on the level of strategy use since their previous response.

Participants responded by texting the numbers corresponding to their ratings for each item ${ }^{1}$.

Once we had collected all the data, we removed the responses containing errors (e.g., insertion of a $15^{\text {th }}$ digit in the sequence), duplications and answers that were sent within $2 \frac{1 / 4}{4}$ hours of the previous or subsequent text message. On average, we received 60 responses to the 70 text messages sent to each participant during the study period (i.e., 86\%).

\section{Measures}

\section{Chronological age.}

Age appears to be a reliable predictor of individuals' perceptions of the time they have left to live, with a strong negative correlation $(r=-.70, p<.001$; Lang \& Carstensen, 2002).

\section{Affects and strategies.}

${ }^{1}$ For example, one response was "311 14251445143 ". The first 12 digits corresponded to the intensity of the 12 affects at the time of the reply. The last two digits corresponded to the levels at which problem solving and positive reappraisal had been used since the previous response. 
The procedure was identical for affects and strategies. Twelve affect definitions were operationalized on the basis of the 12-point affect circumplex (Yik, Russell, \& Steiger, 2011), while problem solving and positive reappraisal were given the definitions that are commonly used in affect regulation research ${ }^{2}$. After the experimenter had read out the definition for an affect or strategy during the initial interview mentioned above, each participant had to summarize this definition by providing what he or she believed to be the most prototypical adjective (for affects) or short sentence (for strategies). This procedure yielded a list of 12 adjectives for each participant, corresponding to the 12 affects, and two short sentences describing the two strategies. These 14 elements formed the items that participants rated in the ESM phase on 5-point Likert scales ranging from 1-Not at all to 5-Very felt (for affects) and used (for strategies). At the end of the interview, to ensure consistency between the adjectives and short sentences chosen by the participants and the target affects and strategies, we submitted each set of items to the participant who had selected them, and asked him or her to restore their meanings. This procedure limited the risk of the same term meaning different things to different participants (Nesselroade, Gerstorf, Hardy, \& Ram, 2007).

The responses given for the 12 affective items at each assessment were subjected to a principal component analysis (PCA) in order to reduce the number of variables. This PCA revealed that three components could explain a substantial part of the variance (i.e., 64\%). The first component was labeled NA, as it saturated the five negatively valenced affects observed in the circumplex model (Yik et al., 2011). The second component was labelled

140 deactivated PA, as it saturated the two deactivated PAs of the model as well as the PA that 141 was neither activated nor deactivated. The third component was labeled activated PA, as it

\footnotetext{
${ }^{2}$ See additional material for more information on the definitions given to participants.
} 
saturated the two activated PAs of the model, as well as the two activated or deactivated affects that were neutrally valenced.

\section{Statistical Analyses}

The data we collected (i.e., the affect experienced by participants and their use of strategies during the ESM phase) formed time series that had to be analyzed using mixed models. However, the nature of these data required more flexible models than generalized linear mixed models (GLMMs; Faraway, 2005). When relationships between variables are more complex than linear ones, as is frequently observed in studies examining the effect of age on affective variables (e.g., Carstensen et al., 2011; Gross et al., 1997; Mroczek \& Kolarz, 1998), GAMMs can provide the flexibility needed to properly describe these relationships.

Moreover, with GAMMs, analyzing nonlinear interactions between quantitative explanatory variables is easier than analyzing them with polynomial-type transformations within the GLMM framework (Marx \& Eilers, 1998; Wood \& Augustin, 2010). GAMMs' aim is not to realize tests of differences between specific age groups, but the graphing is used to approximate these effects descriptively.

GAMMs implemented with the mgcv package (Wood, 2011) in R software (R Core Team, 2015) allowed us to examine the relationship between a person's affective state at a given time and any subsequent use of regulation strategies. To assess the moderating effect of age on this relationship, we included use of the two strategies (during the $t . t_{+1}$ interval $^{3}$ ) as the variable to be explained, and age as the explanatory variable, considered continuously in interaction with the three affective components: NA, deactivated PA, and activated PA. In order to graphically represent the effect sizes, we carried out these analyses using data standardized on the full sample.

\footnotetext{
${ }^{3}$ The participant's estimated level of strategy use during the $t . t+1$ interval was measured at $t_{+1}$.
} 


\section{Descriptive Statistics}

Our first hypothesis concerned the relationship between the age and strategy variables. The correlations in Table 1 between age and the mean level at which each participant used problem solving and positive reappraisal show that, as hypothesized, use of these two strategies increased with age. Moreover, the correlations between age and mean affect per participant suggested moderate age-related differences in affects of the same order of magnitude as that described in the literature with similar methodologies (Carstensen, Pasupathi, Mayr, \& Nesselroade, 2000; Scheibe, English, Tsai, \& Carstensen, 2013; Stone, Schwartz, Broderick, \& Deaton, 2010). Age was negatively correlated with NA and positively correlated with activated PA, whereas its correlation with deactivated PA failed to reach significance.

INSERT TABLE 1 ABOUT HERE

\section{Statistical Modeling}

To study the moderating effect of age on the relationship between affect and the subsequent use of affect regulation strategies (Hypothesis 2), we fitted two GAMMs ${ }^{4}$, with age (interacting with the affects measured at $\mathrm{t}$ ) as predictor, and the strategies used between $\mathrm{t}$ and $t_{+1}$ (i.e., those measured at $t_{+1}$ ) as response variable. Explained deviance was .06 for problem solving $\left(e d f\left(\right.\right.$ age, $\left.\mathrm{NA}_{\mathrm{t}}\right)=7.34, p<.001 ; \operatorname{edf}\left(\right.$ age, $\left.\mathrm{DPA}_{\mathrm{t}}\right)=14.19, p<.001 ; e d f($ age $\left.\left.\mathrm{APA}_{\mathrm{t}}\right)=14.57, p<.001\right)$ and 0.05 for positive reappraisal $\left(\right.$ edf $\left(\right.$ age, $\left.\mathrm{NA}_{\mathrm{t}}\right)=4.98, p<.001$; $e d f\left(\right.$ age, $\left.\mathrm{DPA}_{\mathrm{t}}\right)=11.32, p<.001 ; e d f\left(\right.$ age, $\left.\left.\mathrm{APA}_{\mathrm{t}}\right)=1.00, p<.001\right)^{5}$. In the two models we

\footnotetext{
${ }^{4}$ Model structure: strategy $\mathrm{t}_{\mathrm{t}+\mathrm{1}} \sim \mathrm{s}\left(\mathrm{age}, \mathrm{NA}_{\mathrm{t}}\right)+\mathrm{s}\left(\right.$ age, $\left.\mathrm{DPA} \mathrm{A}_{\mathrm{t}}\right)+\mathrm{s}\left(\right.$ age, $\left.\mathrm{APA}_{\mathrm{t}},\right)+(1$ Participant $)$. ${ }^{5}$ edf $=$ estimated degrees of freedom. A higher edf corresponds to a more complex relationship between the variables.

The indication 't.t+1' of each strategy indicates that it is the level of strategy's use estimated by the individual concerning the ${ }_{t . t+1}$ interval and which is measured at ${ }_{t+1}$.

A higher edf corresponds to a more complex relationship between the variables.
} 
calculated, five out of six interactions were nonlinear ( $e d f$ above 1). In order to represent them, we produced a series of predicted value graphs (Fig. 1). Variations ranging from -.3 to .3 standard deviations indicated modest but notable differences.

\section{INSERT FIGURE 1 ABOUT HERE}

Like the correlations reported above, the GAMM results were consistent with our first hypothesis. Older adults used more problem solving and positive reappraisal than younger adults, regardless of the type of affect experienced beforehand.

Our second hypothesis was generally confirmed by the results on the use of problem solving. When we considered NA (Fig. 1a), we found that the under-20s made little use of problem solving. Individuals aged 20 years or older used this strategy more intensely when they had previously felt high NA, reflecting an increase in reactive regulation with age. By contrast, we only observed an increase in proactive regulation (i.e., problem solving following low NA) among adults aged 55 years or more. When we considered deactivated PA (Fig. 1c), we found that after the age of 20 years, a low level of deactivated PA increasingly led to a high level of problem solving use, reflecting more intense reactive regulation. By contrast, the proactive use of problem solving (i.e., following high deactivated PA) only started to increase at around 45 years. When we considered activated PA (Fig. 1e), we unexpectedly observed the opposite pattern. Adults aged 20 years or more implemented problem solving more proactively than younger individuals, whereas more intense reactive use of this strategy was only observed among individuals aged 55 years or more.

Regarding the use of positive reappraisal, results did not entirely support our hypothesis. As expected, the oldest adults were the ones who used this strategy the most, both reactively and proactively. Moreover, when DPA was considered (Fig. 1d), the hypothesized pattern emerged, insofar as the reactive implementation of positive reappraisal was more intense among adults aged 20 years or more than among younger individuals, whereas the proactive 
use of this strategy increased mainly among adults aged 55 years or more. However, contrary to what we had predicted, we found similar age-related differences in the proactive and reactive use of positive reappraisal when NA and activated PA were considered (Fig. 1b and Fig. 1f).

\section{Discussion}

In summary, our findings confirmed our hypothesis that, compared with their younger counterparts, older adults implement problem solving and positive reappraisal more intensely, both reactively and proactively. This finding is consistent with the idea that, as older adults are more motivated to promote their immediate well-being than younger adults, owing to their perception of the reduced time they have left to live, they engage more in the implementation of affect regulation strategies (Carstensen, 2006; Charles, 2010).

Furthermore, when we analyzed age-related differences in strategy use following experiences of NA and deactivated PA, we observed the hypothesized pattern of differences between reactive and proactive regulation. Participants aged 20 years or more implemented problem solving more intensely and in a reactive manner, probably owing to their eudaimonic approach to wellbeing. By contrast, probably owing to the more hedonic approach to wellbeing displayed by older adults, an increase in the proactive use of this strategy was only observed among individuals aged 55 years or more. An equivalent increase was observed in the proactive use of positive reappraisal following the experience of deactivated PA, but its reactive and proactive uses underwent similar age-related changes whatever the previous level of NA or activated PA.

When we considered strategy use following activated PA, age-related differences in reactive regulation no longer preceded age-related differences in proactive regulation. One possible explanation for this result is that affects are not simply signals triggering regulation activities; they also serve as regulation resources (e.g., Fredrickson, 1998). In particular, 
activated PA may be a useful source of energy for individuals who are less motivated to achieve immediate well-being (i.e., younger adults), as it may make the use of costly affect regulation strategies (e.g., problem solving) easier. By contrast, individuals who are more motivated to achieve immediate well-being (e.g., older adults) may engage in such strategies even when they experience low energy states. In short, if activated PA constitutes a resource, we can assume that young adults use the energy as and when it is available, while older adults engage in strategies such as problem solving even when they lack energy, potentially with the aim of regaining it in the future.

The first limitation of our study was the indirect operationalization, based on previous affective states, of reactive and proactive affect regulation. Our results therefore need to be validated using another procedure that more straightforwardly operationalizes the difference between proactive and reactive regulation. For example, participants could be directly questioned about their approach to regulation: do they use each of the strategies according to their previous affective state or according to the affective state they may experience in the future?

A second limitation is that we included only a few very old adults, owing to the nature of the protocol. This is important, as affective experience has been shown to change in extreme old age. It would be interesting to see whether very old people, who exhibit a decline in wellbeing (Gana, Saada, \& Amieva, 2015), continue to use proactive regulation. A last limitation of this study refers to use of convenience/social network-based sampling.

In conclusion, our analyses yielded evidence of distinct age differences in the reactive versus proactive use of two affect regulation strategies that enhance well-being. Compared with the under-20s, adults aged 20 years or more used the strategies we focused on more intensely and in a reactive manner. More intense proactive use of these strategies was observed solely in older participants, from around 55 years upwards, and solely when strategy 
261 use following NA or deactivated PA. The opposite pattern emerged following activated PA.

262 Although we interpreted our findings in the light of motivational factors (i.e., age differences

263 in eudaimonic vs. hedonic approaches to well-being), these findings need to be replicated and 264 further explained. 
Blanchard-Fields, F., Stein, R., \& Watson, T. L. (2004). Age differences in emotion-regulation strategies in handling everyday problems. The Journals of Gerontology. Series B, Psychological Sciences and Social Sciences, 59(6), 261-269.

Carstensen, L. L. (2006). The influence of a sense of time on human development. Science, 312(5782), 1913-1915.

Carstensen, L. L., Fung, H. H., \& Charles, S. T. (2003). Socioemotional selectivity theory and the regulation of emotion in the second half of life. Motivation and Emotion, 27(2), 103-123.

Carstensen, L. L., Pasupathi, M., Mayr, U., \& Nesselroade, J. R. (2000). Emotional experience in everyday life across the adult life span. Journal of Personality and Social Psychology, 79(4), $644-655$.

Carstensen, L. L., Turan, B., Scheibe, S., Ram, N., Ersner-Hershfield, H., Samanez-Larkin, G. R., ... Nesselroade, J. R. (2011). Emotional experience improves with age: Evidence based on over 10 years of experience sampling. Psychology and Aging, 26(1), 21-33.

Charles, S. T. (2010). Strength and vulnerability integration (SAVI): A model of emotional well-being across adulthood. Psychological Bulletin, 136(6), 1068-1091.

Charles, S. T., \& Pasupathi, M. (2003). Age-related patterns of variability in self-descriptions: Implications for everyday affective experience. Psychology and Aging, 18(3), 524-536.

Clark, M. (2013). Generalized additive models. Retrieved from https://www3.nd.edu/ mclark19/learn/GAMS.pdf

Diehl, M., Chui, H., Hay, E. L., Lumley, M. A., Grühn, D., \& Labouvie-Vief, G. (2014). Change in coping and defense mechanisms across adulthood: Longitudinal findings in a European American sample. Developmental Psychology, 50(2), 634-648.

Diehl, M., Coyle, N., \& Labouvie-Vief, G. (1996). Age and sex differences in strategies of coping and 
defense across the life span. Psychology and Aging, 11(1), 127-139.

Doerwald, F., Scheibe, S., Zacher, H., \& Van Yperen, N. W. (2016). Emotional competencies across adulthood: State of knowledge and implications for the work context. Work, Aging and Retirement, 2(2), 159-216.

Faraway, J. J. (2005). Extending the linear model with R: Generalized linear, mixed effects and nonparametric regression models. Boca Raton London New York: CRC Press.

Fredrickson, B. L. (1998). What good are positive emotions? Review of General Psychology, 2(3), $300-319$.

Gana, K., Saada, Y., \& Amieva, H. (2015). Does positive affect change in old age ? Results from a 22year longitudinal study. Psychology and Aging, 30(1), 172-179.

Gross, J. J. (1998). The emerging field of emotion regulation: An integrative review. Review of General Psychology, 2(3), 271-299.

Gross, J. J. (2015). Emotion regulation : Current status and future prospects. Psychological Inquiry, $26,1-26$.

Gross, J. J., Carstensen, L. L., Pasupathi, M., Tsai, J., Götestam Skorpen, C., \& Hsu, A. Y. C. (1997). Emotion and aging: Experience, expression, and control. Psychology and Aging, 12(4), 590-599.

Gross, J. J., \& Thompson, R. A. (2007). Emotion regulation: Conceptual foundations. In J. J. Gross (Ed.), Handbook of emotion regulation (pp. 3-17). New York: Guilford.

Guisan, A., Edwards, T. C., \& Hastie, T. (2002). Generalized linear and generalized additive models in studies of species distributions: Setting the scene. Ecological Modelling, 157(2-3), 89-100.

Hektner, J. M., Schmidt, J., \& Csikszentmihalyi, M. (2008). Experience sampling method: Measuring the quality of everyday life. European Psychologist, 13(2), 152-153.

Kahneman, D., Diener, E., \& Schwarz, N. (1999). Well-being: Foundations of hedonic psychology. New-York: Russell Sage Foundation. 
Lang, F. R., \& Carstensen, L. L. (2002). Time counts: Future time perspective, goals, and social relationships. Psychology and Aging, 17(1), 125-139.

Le Vigouroux, S., Dauvier, B., Congard, A., Kop, J.-L., Pavani, J.-B., \& Gilles, P.-Y. (2015). Le développement des stratégies de régulation affective au cours de l'âge adulte. L'Année Psychologique, 115(3), 351-383.

Lin, X., \& Zhang, D. (1999). Inference in generalized additive mixed models by using smoothing splines. Journal of the Royal Statistical Society Series B, 61, 381-400.

Löckenhoff, C. E., \& Carstensen, L. L. (2007). Aging, emotion, and health-related decision strategies: Motivational manipulations can reduce age differences. Psychology and Aging, 22(1), 134-146.

Marx, B. D., \& Eilers, P. H. C. (1998). Direct generalized additive modeling with penalized likelihood. Computational Statistics \& Data Analysis, 28, 193-209.

McKeown, G. J., \& Sneddon, I. (2014). Modeling continuous self-report measures of perceived emotion using generalized additive mixed models. Psychological Methods, 19(1), 155-174.

Mroczek, D. K., \& Kolarz, C. M. (1998). The effect of age on positive and negative affect: A developmental perspective on happiness. Journal of Personality and Social Psychology, 75(5), $1333-1349$.

Nesselroade, J. R., Gerstorf, D., Hardy, S. A., \& Ram, N. (2007). Focus article: Idiographic filters for psychological constructs. Measurement: Interdisciplinary Research \& Perspective, 5(4), $217-$ 235.

Pavani, J.-B., Le Vigouroux, S., Kop, J.-L., Congard, A., \& Dauvier, B. (2015). Affect and affect regulation strategies reciprocally influence each other in daily life: The case of positive reappraisal, problem-focused coping, appreciation and rumination. Journal of Happiness Studies. http://doi.org/10.1007/s10902-015-9686-9

R Core Team (2015). R: A language and environment for statistical computing. Vienna, Austria: R Foundation for Statistical Computing. 
Riediger, M., Schmiedek, F., Wagner, G. G., \& Lindenberger, U. (2009). Seeking pleasure and seeking pain: Differences in prohedonic and contra-hedonic motivation from adolescence to old age. Psychological Science, 20(12), 1529-1535.

Riediger, M., Voelkle, M. C., Ebner, N. C., \& Lindenberger, U. (2011). Beyond "happy, angry, or sad?": Age-of-poser and age-of-rater effects on multi-dimensional emotion perception. Cognition \& Emotion, 25(6), 968-982.

Röcke, C., Li, S.-C., \& Smith, J. (2009). Intraindividual variability in positive and negative affect over 45 days: Do older adults fluctuate less than young adults? Psychology and Aging, 24(4), 863878.

Rovenpor, D. R., Skogsberg, N. J., \& Isaacowitz, D. M. (2012). The choices we make: An examination of situation selection in younger and older adults. Psychology and Aging, 28(2), $365-376$.

Ryan, R. M., \& Deci, E. L. (2001). On happiness and human potential: A review of research on hedonic and eudaimonic well-being. Annual Review of Psychology, 52, 141-166.

Scheibe, S., English, T., Tsai, J. L., \& Carstensen, L. L. (2013). Striving to feel good: Ideal affect, actual affect, and their correspondence across adulthood. Psychology and Aging, 28(1), 160-171.

Stone, A. A., Schwartz, J. E., Broderick, J. E., \& Deaton, A. (2010). A snapshot of the age distribution of psychological well-being in the United States. Proceedings of the National Academy of Sciences of the United States of America, 107(22), 9985-9990.

Urry, H. L. (2009). Using reappraisal to regulate unpleasant emotional episodes: Goals and timing matter. Emotion, 9(6), 782-797.

Voelkle, M. C., Ebner, N. C., Lindenberger, U., \& Riediger, M. (2013). Here we go again: Anticipatory and reactive mood responses to recurring unpleasant situations throughout adulthood. Emotion, 13(3), 424-433.

Wood, S. N. (2011). Fast stable restricted maximum likelihood and marginal likelihood estimation of semiparametric generalized linear models. Journal of the Royal Statistical Society (B), 73(1), 3- 
102 Wood, S. N., \& Augustin, N. H. (2010). GAMs with integrated model selection using penalized regression splines and applications to environmental modelling. Ecological Modelling, 157(2-3),

104 $157-177$.

105

Yik, M. S. M., Russell, J. A., \& Steiger, J. H. (2011). A 12-point circumplex structure of core affect.

106 Emotion, 11(4), 705-731.

107 
$108 \quad$ Table and Figure

109 Table 1

110 Correlations Between Age, Affective Components and Regulation Strategies

\begin{tabular}{|c|c|c|c|c|c|c|}
\hline & Age & NA & DPA & APA & PS & PR \\
\hline NA & $-.17^{*}$ & 1 & & & & \\
\hline DPA & .04 & $\begin{array}{l}-.34 * * \\
-.43(.32)\end{array}$ & 1 & & & \\
\hline APA & $.16^{*}$ & $\begin{array}{l}-.06 \\
-.39(.28)\end{array}$ & $\begin{array}{l}.53^{* *} \\
.10(.32)\end{array}$ & 1 & & \\
\hline Problem solving & $.19 *$ & $\begin{array}{l}.19 * * \\
.03(.20)\end{array}$ & $\begin{array}{l}.33^{* *} \\
-.05(.19)\end{array}$ & $\begin{array}{l}.52^{* *} \\
.05(.19)\end{array}$ & 1 & \\
\hline Positive reappraisal & $.16^{*}$ & $\begin{array}{l}.16^{*} \\
.02(.22)\end{array}$ & $\begin{array}{l}.43 * * \\
-.01(.22)\end{array}$ & $\begin{array}{l}.43^{* *} \\
.05(.19)\end{array}$ & $\begin{array}{l}.63^{* *} \\
.26(.26)\end{array}$ & 1 \\
\hline
\end{tabular}

Note. $\mathrm{NA}=$ negative affect; $\mathrm{APA}=$ activated positive affect; $\mathrm{DPA}=$ deactivated positive affect; $P R=$ positive reappraisal; $P S=$ problem solving. First row: interindividual correlations with mean individual levels of affective components and regulation strategies. Second row: mean (standard deviation) intra-individual correlations. 

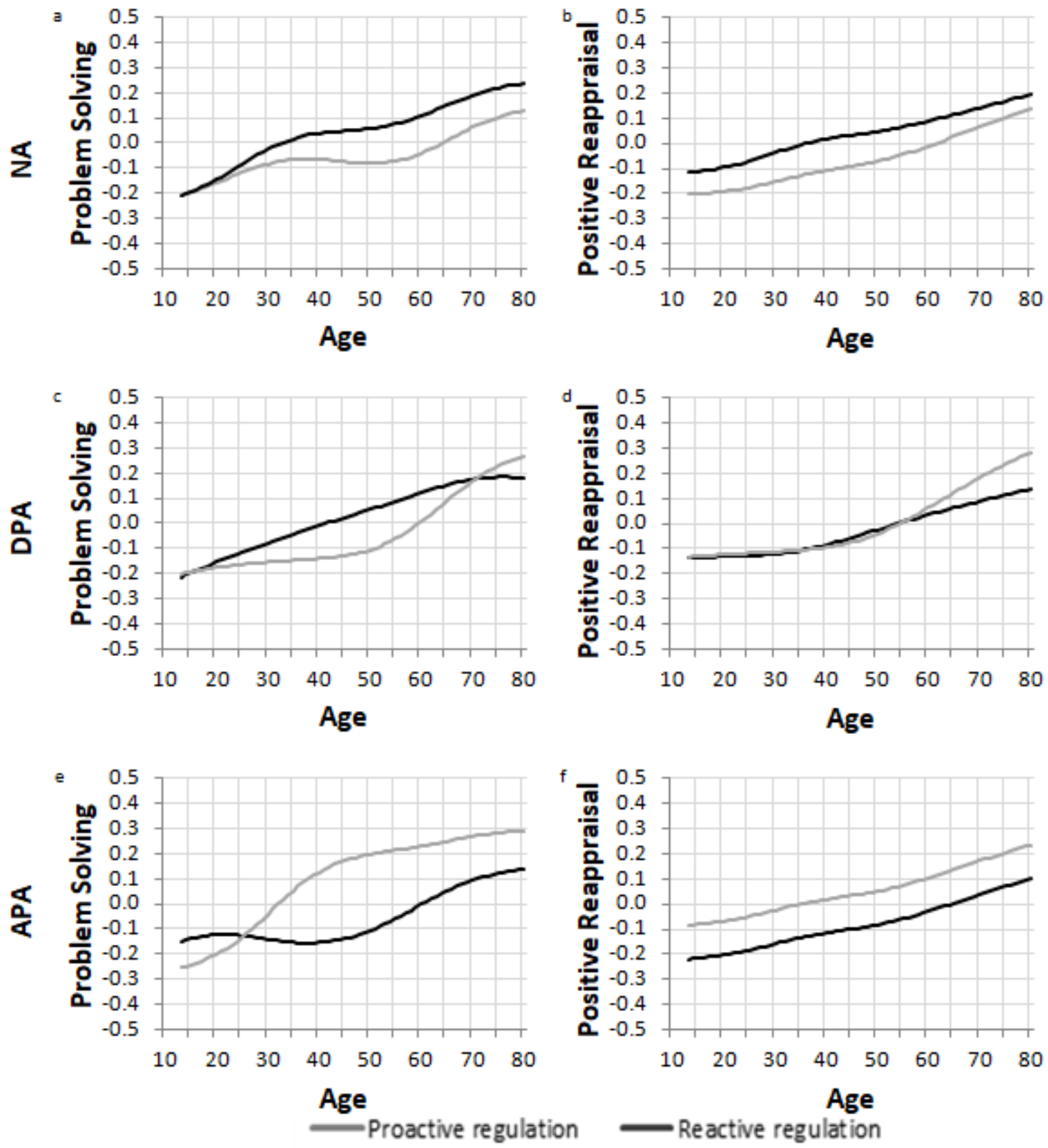

115 Note. NA = negative affect; APA = activated positive affect; DPA = deactivated positive affect.

116 Reactive regulation corresponds to the use of strategies following a period of reduced well-being (high NA / low APA and/or DPA). Proactive regulation corresponds to the use of strategies following a period of high wellbeing (low NA / high APA and/or DPA). The level of strategy use was standardized. For each graph, the predicted values were estimated for a value of \pm 1 standard deviation for the relevant affective component, while the other two affective components were set at the mean (means and standard deviations computed on all observations). The black (reactive) curve corresponds to +1 SD of NA or -1 SD of DPA and APA. The grey (proactive) curve corresponds to -1 SD of NA or +1 SD of DPA and APA. 
Figure 1.Generalized additive mixed model predictions for the proactive versus reactive

125 use of cognitive reappraisal and problem solving for affect regulation, in interaction with age. 